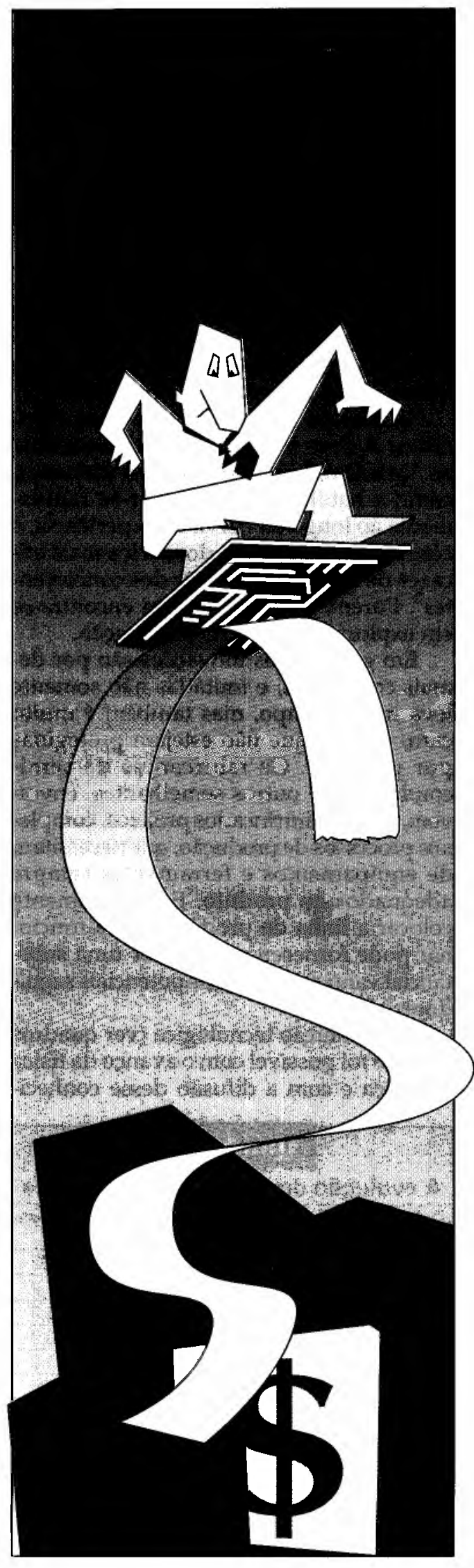

Revista de Administração de Empresas

\section{A DINÂMICA DO MERCADO HIGH-TECH}

$\star$ George Bedinelli Rossi

Nesta era em que o domínio da mente sobre a matéria revela-se como o ativo mais importante da empresa, a função básica da gerência é criar um clima que favoreça a inovação.

In this age, when mind domain over matter is seen as the most important asset by the firm, managers must create an environment that encourage innovation.

PALAVRAS-CHAVE:

tecnologia, informática, vantagem competitiva, informação, mercado, high-tech, competição, estratégia mercadológica, inovação, comportamento do consumidor, economia de escala, negócios, investimentos tecnológicos.

KEY WORDS:

technology, informatics, competitive advantage, information, market, high-tech, competition, marketing strategy, innovation, consumer behavior, economy of scale, business, technological investiments.

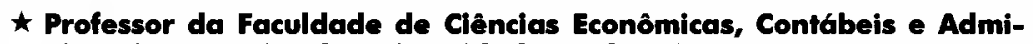
nistrativas (FCECA) da Universidade Mackenzie.
} 
1. FERGUSON, C. H. Computers and the coming of the U.S. Keiretsu. Harvard Business Review, Boston, v. 68, n. 4 , p. 55-70, July/Aug. 1990; RAPPAPORT, A. S., HALEVI, S. The computerless computer company. Hanvard Business Review, Boston, v. 69 , n. 4, p. 72, July/ Aug. 1991; HOWARD, R. The CEO as oroanizational architect: an interview with xerox's Pau Allaire. Harvard Business Review Boston v 70, n. 5 o. 107-110, Sept./Oct. 1992 WEISS, S. A. Lessons from the rise and fall of nations. Harvard Business Review, Boston, v. 66 , n. 2, p. 24, Mar./Apr. 1988.

2. WEISS, A. M., HEIDE, J. B. The nature of organizational search in high technology markets. Journal of Marketing Research, v. XXX, п. 2, p. 220, May 1993.

3. Lei do Microcosmo: em grandes volumes, tudo dentro do chip é barato. Mas, no momento em que se vai para fora do chip os precos sobem exponencialmente. Enquanto uma conexāo dentro de um chip custa alguns milionésimos de centavos de dólar, um fio numa placa de circuito impresso sai por volta de 10 centavos. GILDER, G. Microcosm. New York: Simon \& Shuster, 1989, p. 346.

4. Idem, ibidem, p. 122-26. P. Haggerty, presidente da Texas Instruments foi quem primeiro percebeu que o negócio de semicondutores era de fato orientado a grandes volumes de produçāo.

5. Idem, ibidem, p. 125; SAY, JEAN-BAPTISTE. Lei de Say. In: E. K. Hunt (Org.). Mistória do Pensamento Econômico. 7. ed. Rio de Janeiro: Campus, 1989. p. 155.

6. NELSON, R. R. What is "commercial" and what is "public" about technology, and what should be. In: ROSENBERG, N. LANDAU, R., MOWERY, D.C Technology and the wealth of nations. Stanford, California: Stanford University, 1992, p. 63. estudo de mercados high-tech tem despertado a atençāo e o interesse não somente de pesquisadores, como também, e sobretudo, de empresas e governos ${ }^{1}$. O termo high-tech é usado para definir mercados com rápida evolução tecnológica (ver quadros 1 e 2) e ampla variedade de alternativas tecnológicas, o que implica a falta de uma tecnologia dominante ${ }^{2}$.

A falta de uma tecnologia dominante impulsiona o comprador de produtos hightech a realizar amplos esforços na busca de informaçōes para manter-se atualizado. Isto se deve essencialmente à rápida obsolescência do seu "estoque" de conhecimentos, acerca dos atributos e características dos produtos que se encontram em rápida e constante evolução. Por outro lado, a heterogeneidade tecnológica (ampla variedade de padrōes tecnológicos em forma de produtos), assim como o ritmo da evolução tecnológica, representam uma outra forma de incerteza que, para ser resolvida, implica uma extensa busca de informaçōes.

Neste sentido, a indústria de informática revela-se como a que mais tem evoluído no menor espaço de tempo (ver quadros 1 e 2). A análise desses quadros revela, também, que esta indústria apresenta como peculiaridade o fato de que, enquanto o poder de seus produtos aumenta (número de transistores numa pastilha de silício ou o total de instruçōes por segundo), esses mesmos produtos diminuem em tamanho físico. Isto é, crescem para dentro, fenômeno este descrito por George Gilder como a "Lei do Microcosmo"

Assim, quanto maior o número de transistores em uma pastilha de silício, maior será sua capacidade (de armazenamento ou de processamento) e menores serão seu tamanho físico e seu custo unitário. A dinâmica deste processo é, entāo, maior capacidade, menor custo e mais vendas, um processo conhecido como curva de experiência, a partir de um estudo efetuado por B. Henderson (Boston Consulting Group), da Texas Instruments.

O sucesso do computador - e sua ampla aceitação e uso por parte de amplos setores da sociedade enquanto produto pode ser explicado por dois fatores. Primeiro pela curva de experiência, ou seja, com o aumento da produção diminuem-se os custos, barateando o produto, permitindo assim alcançar outros segmentos de mercado. Isto é, ao se diminuírem os custos, aumenta-se a demanda, que por sua vez
Quadreo 1

Os novos superchips

\begin{tabular}{|l|r|r|r|r|r|}
\hline & 1980 & 1985 & 1987 & 1990 & 1995 \\
\hline $\begin{array}{l}\text { Comprimento do } \\
\text { circuito (microns) }\end{array}$ & 04 & 02 & 01 & 0.5 & 0.25 \\
\hline $\begin{array}{l}\text { Capacidade de } \\
\text { memória (Kbytes) }\end{array}$ & 64 & 256 & 1024 & 4096 & 16384 \\
\hline
\end{tabular}

Fonte: FORRESTER, T. High-tech society. Cambridge, Massachusetts: The Mit Press, 1987, p. 2.

forçará nova queda nos custos, expandindo, então, os mercados, o que novamente forçará a novas quedas nos custos, e assim por diante. O segundo fator é a lei de Say: a oferta gera sua própria demanda ${ }^{4}$.

$\mathrm{Na}$ maioria das indústrias - em especial as high-tech - a vantagem associada ao "primeiro" (ou inovador, ou pioneiro), como a habilidade em mover-se rapidamente ao longo da curva de experiência, é considerada como um dos meios mais eficazes de se manter à frente dos concorrentes ${ }^{5}$. Porém, a real vantagem encontra-se em explorar os ganhos da inovação.

Em geral, essas inovaçōes săo por demais complexas, e imitá-las não somente leva muito tempo, mas também é muito caro, mesmo que năo estejam protegidas por patentes. Os fabricantes de semicondutores, e outros semelhantes, envolvem, além de intrincados projetos, complexos processos de produção, que necessitam de equipamentos e ferramentas sempre adequados ao produto. E simplesmente colocar a linha de produção para funcionar pode fornecer ao inventor uma substancial vantagem sobre os potenciais seguidores 6 .

Esta evoluçāo tecnológica (ver quadros 1 e 2) só foi possível com o avanço da física quântica e com a difusāo desse conheci-

\section{Duadrow 2}

A evolução dos microprocessadores

\begin{tabular}{|l|l|r|r|}
\hline $\begin{array}{l}\text { Data de } \\
\text { introduçāo }\end{array}$ & $\begin{array}{l}\text { Nome do } \\
\text { chip }\end{array}$ & $\begin{array}{r}\text { Número de } \\
\text { transistores }\end{array}$ & $\begin{array}{l}\text { Poder em } \\
\text { MIPS }^{*}\end{array}$ \\
\hline Junho/1978 & 8086 & 29.000 & 0,33 \\
\hline Fevereiro/1982 & 80286 & 134.000 & 1,2 \\
\hline Outubro/1985 & $803860 X$ & 275.000 & 6,0 \\
\hline Abril/1989 & $4860 X$ & 1.200 .000 & 20,0 \\
\hline Março/1992 & $4860 \times 2$ & 1.200 .000 & 40,0 \\
\hline Maio/1993 & Pentium ${ }^{\text {m }}$ & 3.100 .000 & 112,00 \\
\hline 20 Semest./1995** $^{*}$ & P6 & 5.500 .000 & 250,0 \\
\hline
\end{tabular}

* Milhōes de instruçōes por segundo.

* Previsāo de lançamento. Fonte: Byte. Abril/1995, p. 34.

Fonte: HOFFMAN, G. M. The technology payoff. How to profit wiht empowered workers in the information age. New York: Richard D. Inwin, 1994, p. 13. 
mento para além das empresas pioneiras nestes mercados, dando origem a várias outras empresas e criando, assim, um dos maiores (senão o maior) mercados competitivos da história, em que o foco central da competição é o conhecimento (profundo, relativo à física quântica). Se, por um lado, criaram-se várias empresas high-tech, por outro, criou-se mútua dependência entre elas. Não mais é possível a uma única empresa deter profundo conhecimento não somente sobre a imensa gama de produtos deste setor (como memórias, microprocessadores etc.), como também sobre todas as etapas do processo produtivo e de vendas de um único componente. Os recursos necessários ao projeto, à fabricação e à distribuição, são hoje realizados por várias empresas, embora ainda existam aquelas que tudo fazem ou tencionem fazer .

Eé justamente a conjunção da Lei de Say com a curva de experiência que rege as estratégias que alcançam o sucesso nos mercados high-tech. A principal razão por que inovadores com boas idéias (que se transformam em bons produtos do ponto de vista mercadológico) falham em abrir mercados, de forma sucessiva, é que operam em um ambiente no qual seu know-how é difícil de ser protegido. As duas mais importantes formas de proteção são a legal, via patentes ou outras formas legais, e a natureza da tecnologia.

A primeira forma, proteção legal, mesmo quando obtida em sua plenitude, ainda assim pode ser contornada por invenções parecidas a custos muito menores. Assim, a segunda forma de proteção torna-se mais crítica. Uma vez que um novo produto emerge como tecnologia dominante, a competição centra-se nos preços e não mais no projeto em si. Com isso, a escala de produção e o aprendizado tornamse muito mais importantes e o respectivo capital especializado é desenvolvido e empregado, enquanto o pioneiro procura baixar seus custos unitários pela exploração das economias de escala e do aprendizado. Ao contrário da incerteza gerada pela ausência de uma tecnologia dominante, que implica baixos volumes de produção (em razão do risco), a identificação da tecnologia dominante implica um incremento no volume e no surgimento de oportunidades para as economias de escala, que, por sua vez, acarretam a produção em massa pela aquisição de ativos especializados. Estes ativos ou têm ou desenvol- vem atributos específicos à empresa que os detêm, sendo que as suas peculiaridades podem estar no capital físico, conhecimento especializado, localização e outras especificidades. Eles são, via de regra, difíceis de imitar, o que os tornam valiosos como importante fonte de vantagem competitiva.

Porém, não é raro o caso em que o inventor, após conseguir o capital necessário ao início de sua empresa, percebe a falta de know-how em outras áreas, além do desenvolvimento e da produção: como não ter acesso aos canais de distribuição ou, de forma mais ampla, não ter a capacitação necessária à promoção $\mathrm{e}$ distribuição de seus produtos, e, em alguns casos, não conseguir gerar capacidade produtiva suficiente para atender à demanda do mercado em tempo hábil. Isto, por sua vez, impulsiona uma ação mais agressiva por parte de seus concorrentes mais capacitados nestas áreas. Assim, a forma como o inovador pode manter-se à frente da concorrência é complementando seus ativos com os ativos de outras empresas ${ }^{8}$.

Conseqüentemente, a posse ou controle dos ativos específicos são a fonte de uma vantagem competitiva sustentável. $O$ paradoxo aqui centra-se no fato de que alguém pode colher ou se apropriar dos lucros de uma invenção sem ser necessariamente o seu inventor.

A forma encontrada pelos inovadores (ou inventores) para não serem expropriados dos lucros de suas invenções foi a formação de alianças (ou parcerias estratégicas) com empresas de maior porte (ou detentoras de ativos complementares aos do inovador). Estas alianças estratégicas aumentaram nos últimos anos e são particularmente uma característica das indústrias high-tech. Assim, fato comum foi a formação de alianças entre as pequenas empresas inovadoras e as grandes, em razão de estas Gltimas terem ou controlarem um portfolio de ativos especializados ou coespecializados ${ }^{9}$. Hoje é normal as alianças entre as grandes (e entre as pequenas), a fim
7. GILDER, G. Op. cit., 343-44.

8. TEECE. D. J. Capturing the financlal benefits from technological inovations. In: ROSENBERG, N., LANDAU, R., MOWERY, D.C. Op. cit., p. 197

9. Idem, ibidem, p. 177-94. 
10. Como, por exemplo, a formação da aliança entre a IBM, Apple e Motorola para o projeto, desenvolvimento e fabricaçāo do processador Power PC, a fim de diminuírem o poder da Intel nesta classe de produtos.

11. ERHORN, C., STARK, J. Competing by design. Creating value and market advantage in new product development. Essex Junction, VT: Oliver Wight, 1994, p. 29.

12. STALK JR., G. Time - the next source of competitive advantage. In: MONTGOMERY, C.A., PORTER, M. E. Strategy - Seeking and securing competitive advantage. Boston, MA: Harvard Business Review Book Series, 1991, p. 39

de complementarem suas capacidades específicas ${ }^{10}$.

Estas alianças, por permitirem concentrar esforços em competências principais, criam uma situação positiva para todas as empresas, pois, para competirem eficazmente, mais e mais empresas procedem ao desenvolvimento de equipamentos técnicos, o que lhes permite inovar com mais rapidez e flexibilidade ${ }^{11}$. Esta rapidez imprime nova dimensão à dinâmica do mercado, que é o fator tempo. O fator tempo é um elemento vital à sobrevivência, ou mesmo ao sucesso empresarial, já que lançar novos produtos ao mercado antes da concorrência - ou mesmo desenvolver novas tecnologias antes da concorrência - é a principal fonte de competição ${ }^{12}$.

Esta concentração de esforços reduz, assim, a importância das grandes empresas, já que os ativos destas são, via de regra, mais genéricos do que os das pequenas empresas. Ao fazermos esta análise com base na cadeia de valores de Porter ${ }^{13}$, verificamos que cada uma das atividades primárias é executada por uma empresa, que se especializou essencialmente em uma atividade específica (produção, desenvolvimento, marketing e vendas etc.). Neste sentido, temos que o sistema de valores, segundo Porter, é de fato não mais o somatório das diver-

Na essência, as grandes empresas olham para os novos mercados pelos olhos de seus clientes atuais e no contexto de sua estrutura financeira corrente. sas cadeias de

valores de várias empresas, mas sim a inter-relação das diversas atividades de valor agora desempenhadas por empresas específicas.

Este alto grau de especialização aumenta substancialmente a importância do fator tempo como fonte de vantagem competitiva, pois a rapidez em se alcançar mercados tornou-se crítica, já que o importante não é somente lançar novos produtos ao mercado, mas, acima de tudo, identificar os produtos que detêm respostas mais favoráveis por parte do mercado, a fim de adequar a oferta à demanda no menor espaço de tempo.

O caso da Toshiba America é ilustrativo. Em vez de realizar complexos e demorados processos internos de decisão baseados em limitados testes de mercados relativos a quais produtos lançar, lança-os ao mercado, deixando que este identifique quais produtos quer $e$, por conseguinte, quais serão sucessos mercadológicos. Esta estratégia de experimentação no mercado sobre a aceitação de produtos, além de muito eficaz, deixa poucas dúvidas de quais produtos continuar a produzir ou retirar do mercado, e quais devem ser reajustados às suas necessidades e desejos ${ }^{14}$. Embora o lançamento de novos produtos seja importante, estes sucessivos lançamentos da Toshiba America revelam que, o fator crítico é o foco no produto, que representa a inovação tecnológica. Conseqüentemente, os ciclos de vida são uma característica muito bem delineada dos produtos hightech. Entretanto, o curto ciclo de vida do produto não é o ponto crítico, mas sim o curto ciclo de vida de mercado. Os ciclos de vida de mercado e de produto são curtos devido às mesmas razões: tecnologias novas ou emergentes impulsionam o mercado para uma direção diferente ${ }^{15}$.

Essa nova direção mostra-se tanto uma oportunidade para as novas (ou pequenas) empresas como um alto risco (perigo) para as grandes. A dinâmica desse paradoxo é que novas tecnologias (ou emergentes) em geral não são percebidas pelas grandes empresas como potencial de lucros. A razão para tal é que, já que as grandes empresas estão comprometidas com as tecnologias em uso e amplamente aceitas pelo mercado (em especial pelos clientes mais importantes dessas empresas), buscam sobretudo o aprimoramento das tecnologias correntes.

A busca desse aprimoramento - e seu sucesso em geral - segue uma curva tipo "S", em que, a partir de um certo limite, a evolução da tecnologia corrente torna-se muito lenta em razão principalmente da aproximação do limite máximo que esta tecnologia pode alcançar. E isto deve-se em essência à máxima de marketing de que as empresas devem focar sua atenção em seus clientes. O paradoxo desta situação é que os clientes sempre irão preferir produtos com maior performance na tecnologia por eles adotada. Além desse, outro fator de risco às grandes empresas é a questão dos lucros. Pois, em geral, as novas tecnologias, quando de seu lançamento ao mercado, têm um desempenho técnico inferior ao das já estabelecidas. Um terceiro fator é que as novas tecnologias representam um pequeno potencial para a realização de lucros, o que inibe ainda mais a sua adoção por 
parte das grandes empresas, que já contam com amplos investimentos a serem amortizados.

Grandes empresas usam o planejamento e os sistemas orçamentários a fim de selecionar os projetos concorrentes (dentro da própria empresa) aos quais alocar fundos. Propostas para a criação de novos negócios nos mercados emergentes têm poucas chances de obtenção de fundos porque dependem de estimativas de tamanho de mercado, que nesta fase são de pouca confiança. E, porque os gerentes são avaliados por sua habilidade em obter os maiores lucros possíveis por projeto, é comum apoiar os projetos para os quais haja mercado assegurado. Também, por estarem perto dos principais clientes, como foram ensinados a proceder, eles focam seus recursos de modo a preencher, assim, os requisitos destes clientes para a realização de lucros. Desta forma, reduzem os riscos - empregos e carreiras ficam garantidos - ao prover aos clientes o que estes querem. $\mathrm{Na}$ essência, as grandes empresas olham para os novos mercados pelos olhos de seus clientes atuais e no contexto de sua estrutura financeira corrente.

Por outro lado, as novas tecnologias oferecem atributos muito diferentes daqueles que historicamente são valorizados pelos principais clientes, e com freqüência apresentam desempenho técnico inferior ao desejado por esses clientes. Porém, à medida que as novas tecnologias começam a ser usadas em novos mercados (ou em novas aplicaçōes), e são por estes valorizadas, outros mercados começam a seguir o exemplo dos primeiros, e assim sucessivamente, até que a nova tecnologia substitua a anterior ${ }^{16}$. A razāo por que novos mercados sāo criados é que de fato novos e diferentes conjuntos de atributos, ou novas combinações de atributos, são ofertados ${ }^{17}$. A causa primária deste aparente paradoxo não está no fato de que as coisas estejam sendo feitas de maneira imprópria ou. mesmo erradas (em muitos casos são feitas corretamente, porém, com resultados ineficazes), mas sim está no fato de que as premissas nas quais as organizações se baseiam distanciaram-se da realidade. Essas premissas centram-se em identificar mercados e concorrentes, seus valores e comportamentos. Centram-se também na tecnologia e em sua dinâmica e nas forças e fraquezas da empresa. Essas premissas são o que Drucker chama de Teoria dos $\mathrm{Ne}$ - gócios, isto é, cada organização desenvolve sua própria teoria a respeito do(s) negócio(s) em que atua ${ }^{18}$.

Quando do surgimento dos

PCs, as principais empresas de computadores da época (IBM, Burroughs, Univac, DEC, HP, Control Data e Data General) deixaram de adotar esta nova tecnologia, à exceção da IBM, por verem o PC com os mesmos olhos com que viam o main-frame. Em seus termos mais básicos, estes produtos se contradizem na definição de informação, pois, para o ambiente mainframe, informaçāo significa memória, enquanto para o PC informação significa software ${ }^{19}$. E quando se interligam os $\mathrm{PCs}$, via rede, com os servidores, esse conjunto apresenta performance compativel com as necessidades de muitas organizações (diminuindo a importância dus main-frames) ${ }^{2 n}$. Assim, o que se tem é a passagem de uma tecnologia voltada ao armazenamento de dados (main-frames) para outra, voltada ao uso desses dados (PCs ou micros). Do coletivo para o individual, do centralizado para o descentralizado.

$E$ isso necessariamente leva a entender a dinâmica de transição tecnológica por parte do mercado (o comprador). Os compradores potenciais não adotam as novas tecnologias imediatamente, não importando quais sejam as vantagens destas sobre suas predecessoras. O mercado se adapta e aprende sobre estas novas tecnologias quando elas estabelecem seu próprio processo de difusão. Isto é, há um aprendizado tardio sobre as vantagens das novas tecnologias ${ }^{21}$.

Historicamente, os cursos de ação adotados para a finalidade acima (conscientemente ou não) têm sido tanto as estratégias para influenciar a demanda quanto as estratégias para criar mudanças macroambientais. As estratégias para influenciar a demanda nos mercados hight-tech têm
16. BOWER, J. L., CHRISTENSEN, C. M. Disruptive technologies: catching the wave Harvard Business Review Boșton, v. 73. n. 1, p. 43-8, Jan./ Feb. 1995.

17. NORTON, J.A., BASS, F.M Evolution of technological generation: the law of capture. Sloan Management Review, v. 33, n. 2, p. 66, Winter 1992.

18. DRUCKER, $P$. Theory of the business. Harvard Business Review, Boston, v. 72 , n. 5 , D 95-8, Sept./Oct. 1994

19. Idem, ibidem, p. 97.

20. BOWER, J. L., CHRISTENSEN, C. M. Op. cit. p. 50 ; MAINFRAMES diminuem sua participação no mercado. Gazeta Mercantil, São Paulo, 21.021995, p. 13

21. NORTON, 1. A., BASS, F. M. 0p. cit., p 67. Para maiores detalhes sobre processos de difusão e processos de aprendizagem, ver: ENGEL, J. F. BLACKWELL, R.D., MINIARD, P. M. Consumer behavior. 7 . ed Fort Wornt, TX: The Dryden Press, 1993. 
22. VARADARAJAN. P. R., CLARK, T., PRIDE, W. M. Controlling the uncontrollable. Sloan Management Review, v. 33, $\mathrm{n}$. 2, p. 42-3, Winter 1992. Como exemplo desta estratégia tem-se a Apple, que incorporou a planilha de dados Visicalc ao seu produto, criando assim o AppleII, que se tornou o maior sucesso de vendas em sua época, eliminando seus então concorrentes. In: FERGUSON, C. H, MORRIS, C.R. Computer wars. New York: Times Books, 1994, p. 20

23. Idem, ibidem, p. 44.

24. BOWER, J. L., CHRISTENSEN, C.M. Op. cit., p. 48.

25. MINTZBERG, $H$. The structure of organizations. In: MINTZBERG, H., QUINN, J. B. The strategy process. New Jersey: Prentice-Hall, 1992, p. 173. focado o marketing estimulante, cujo objetivo é criar demanda positiva para um produto que não tem nenhuma. Isto exige que se altere o ambiente, a fim de aumentar o valor do produto ${ }^{22}$.

Quanto às estratégias para criar mudanças macroambientais, as do tipo novo jogo, por redefinirem as regras, fronteiras e comportamentos de mercado a fim de adaptarem o ambiente às forças da empresa, têm sido largamente utilizadas. Isto é, esta estratégia trata de mudar a percepção do mercado relativa aos atributos dos produtos $^{23}$. Como por exemplo, foi o caso dos discos rígidos de $3^{1 / 2^{\prime \prime}}$ e depois os de $5^{1 / 4^{\prime \prime}}$, que tiveram como principais atributos tamanho e peso em vez de capacidade de armazenamento de dados e preço. Também esse fato ocorreu com os microcomputadores lap-top e notebook, destinados a um mercado então emergente e promissor ${ }^{24}$.

Esse caso ilus-

A reviravolta consiste no fato
de que esta tecnologia tem por
base a física quântica, que
desvaloriza os recursos
materiais (matérias-primas) e
valoriza o conhecimento. Esta
nova revolução industrial é
a revolução da mente
sobre a matéria.

tra também a importância do compromisso da alta gerência com a inovação e, por sua vez, com os empreendedores. Estes, por sua vez, são a essência das empresas high-tech: mantêlos e estimulá-los não somente é crucial à realização de lucros, mas também à sobrevivência da empresa. Pois, neste mercado, o elemento essencial é o conhecimento, e este, por sua vez, está nas pessoas. Quando estas, por qualquer motivo que seja, saem da empresa, estão na verdade levando consigo o ativo mais valioso que a empresa pode ter: o conhecimento.

O ponto central desta abordagem é que, em empresas que tenham como base produtos altamente complexos e cujo ritmo de evolução tecnológica seja alto, torna-se impossível a uma única pessoa - ou grupo restrito de pessoas - ter e deter todo o conhecimento relativo a um produto, desde o projeto até sua fabricação (os processos de fabricação). Esta situação põe por terra a tradicional estrutura hierárquica, já que o conhecimento se encontra disperso por toda a empresa. Isto é, a criação de um produto é, na realidade, a resultante do somatório de esforços de várias pessoas, pois titiveness. The Journal of siness Strategy, v. 12, n. 5, p. 58 , Sept./Oct. 1991. cada uma sabe apenas uma pequena parcela, porém sabe-a em um nível muito profundo: é a figura do especialista ${ }^{25}$.

Assim, a função da alta gerência não deve ser vista como a de definir, controlar ou alocar competências, mas antes como a de criar um ambiente que permita o desenvolvimento e a difusão destas competências de forma profunda dentro da organização ${ }^{26}$.

Nas indústrias high-tech, por exemplo a de semicondutores, estes aspectos são essencialmente os determinantes do sucesso empresarial. A principal dificuldade enfrentada por muitas empresas nesta área é a percepção de que os materiais, e conseqüentemente a sua alocação e obtenção, não representam mais a competência básica empresarial. Enquanto na época da $\operatorname{Re}-$ volução Industrial era essencial a obtenção de matérias-primas, e por conseguinte o seu uso eficaz era caracterizado como sendo a eficiência alocativa (lucratividade) e a eficiência técnica (minimização de custos) ${ }^{27}$, nas empresas high-tech os custos de matérias-primas são literalmente irrisórios, pois, para uma empresa de semicondutores, são o silício (areia) e alumínio (bauxita), os materiais mais abundantes da terra. A reviravolta consiste no fato de que esta tecnologia tem por base a física quântica, que desvaloriza os recursos materiais (matérias-primas) e valoriza o conhecimento. Esta nova revolução industrial é a revolução da mente sobre a matéria ${ }^{28}$.

O valor de um videocassete não repousa em seus atributos físicos, mas sim naquilo que oferece ao seu usuário: a informação (neste caso o filme). Este mesmo raciocínio aplica-se aos CDs, cujo valor está na música (a informação) e não nos aspectos físicos. $\mathrm{O}$ importante não é o meio no qual se encontra a informação, mas sim a informação em si. Chips de memórias, de microprocessadores ou mesmo CD-ROM custam poucos dólares. Porém, se algum deles contiver o sistema operacional de um novo main-frame IBM, a Fujitsu pagará algo em torno de US $\$ 700$ milhões para tê-lo ${ }^{29}$.

Em suma, a inovação aumenta o valor da produtividade dos recursos materiais (matérias-primas) empregados por uma indústria muito mais do que a simples $\mathrm{e}$ mera realocação de tais materiais ${ }^{30}$. $\square$

\section{2}

